\title{
Hyperglycemia: The Metabolic Syndrome Component That Aggravates Erectile Dysfunction in Mexican
}

\section{Patients}

Alan Espinosa-Marrón ${ }^{\mathrm{a}}$, Christian A. Quiñones-Capistrán ${ }^{\mathrm{b}}$, Aquiles Rubio-Blancas ${ }^{\mathrm{a}}$, María del Pilar Milke-García ${ }^{\mathrm{a}}$, Ricardo A. Castillejos-Molina ${ }^{\mathrm{b}, *}$.

aDivision of Nutrition, National Institute of Medical Sciences and Nutrition “Salvador Zubirán”, Vasco de Quiroga 15, Sección XVI, Tlalpan, 14000. Mexico City, Mexico.

bDivision of Urology, National Institute of Medical Sciences and Nutrition “Salvador Zubirán”, Vasco de Quiroga 15, Sección XVI, Tlalpan, 14000. Mexico City, Mexico.

\section{*Corresponding author:}

Ricardo A. Castillejos-Molina.

Postal Address: Vasco de Quiroga 15, Sección XVI, Tlalpan, 14000. Mexico City, Mexico.

Email: rcastillejos@hotmail.com

Tel: (00) (52) 5554870900 ext. 2260

\section{Compliance with Ethical Standards}

The authors declare that they have no conflict of interest.

\section{Financial disclosure statement}

This study did not receive any specific grants from agencies of the public sector, commercial sector or non-profit entities.

\section{Ethical approval}

All procedures performed in studies involving human participants were in accordance with the ethical standards of the institutional and national research committee (National Institute of Medical Sciences and Nutrition's Ethics Committee, URO-844-13/13-1) and with the 1964 Helsinki declaration and its later amendments or comparable ethical standards. 


\begin{abstract}
Introduction and objectives: a close association between metabolic syndrome among subjects with erectile dysfunction has been addressed, since mechanisms underlying metabolic syndrome compromise the blood flow to the penis in numerous ways. This study aims to analyze the relationship between erectile dysfunction and metabolic syndrome in a group of Mexican patients, to study the influence of other morbidity factors on erectile dysfunction, and to define the specific metabolic syndrome components most associated with erectile dysfunction severity. Methods: a descriptive and cross-sectional study was completed in a group of 86 adult Mexican patients with previous diagnosis of erectile dysfunction. Participants were classified as with or without metabolic syndrome. Erectile dysfunction severity, alcohol or tobacco consumption, and depressive behavior were identified through validated questionnaires and compared between both groups, as well as anthropometric, biochemical, and clinical parameters. Results: anthropometric measures, laboratory values, clinical characteristics and the Beck Depression Inventory score were significantly different among both groups. Additionally, more patients affected by severe and moderate erectile dysfunction were identified in the group with metabolic syndrome. Among the metabolic syndrome components, $\mathrm{HbA} 1 \mathrm{c}>5.7 \%$ and fasting glucose $>110 \mathrm{mg} / \mathrm{dl}$ were significantly associated to the development of erectile dysfunction ( $p=0.004$ and 0.04 , respectively). Conclusions: metabolic syndrome components aggravate erectile dysfunction, particularly the lack of glycemic control manifested by Hb1Ac $>5.7 \%$ and/or fasting glucose $>110 \mathrm{mg} / \mathrm{dL}$. The inclusion of fasting glucose and HbA1c as a complementary biochemical screening among patients with erectile dysfunction should be assessed.
\end{abstract}

\title{
Keywords
}

erectile dysfunction; metabolic syndrome; risk factors; hyperglycaemia 


\section{Introduction}

Metabolic syndrome (MetS) refers to a set of multifactorial alterations that raise the risk of developing type 2 diabetes mellitus (T2DM) and cardiovascular disease ${ }^{1}$. Different International Institutions have proposed diagnostic criteria; however, the Adult Panel Treatment (ATP III) incorporated standardized-key concepts so it is one of the most frequently used criteria in clinical practice for the diagnosis of MetS: (i) blood pressure ( $\geq 130 / \geq 85 \mathrm{mmHg}$ ), (ii) high-density lipoprotein cholesterol (HDL-C $<40 \mathrm{mg} / \mathrm{dL}$ ), (iii) triglycerides ( $\geq 150 \mathrm{mg} / \mathrm{dL}$ ), (iv) waist circumference (WC $>102 \mathrm{~cm}$ ), ( $v$ ) fasting glucose $(\geq 100 \mathrm{mg} / \mathrm{d} / \mathrm{L})$. The existence of three of five of these criteria establishes a positive diagnosis ${ }^{2}$. MetS affects up to $30 \%$ of the population in developed countries and its incidence continues to rise $^{3}$. The prevalence of this condition among Mexican men varies from 45.3 to $46.4 \% \%^{4,5}$.

Erectile dysfunction (ED) refers to the inability to achieve an erection as part of the multifaceted process of male sexual function. ED is common among men over 50 years of age ${ }^{6}$. Etiological factors include anatomic, vascular, psychological, neurological and hormonal disorders ${ }^{7}$. It is estimated that $51.1 \%$ of Mexican men between 40 and 60 years old may elicit changes in the erectile function, $59.8 \%$ of them being diagnosed with overt $\mathrm{ED}^{6}$. Furthermore, projections have established that the world's population with ED will reach 322 million cases by $2025^{6}$.

Prevalence of MetS among subjects with ED varies between 29.4 and $79 \%$ worldwide ${ }^{8,9}$. Several studies have found a close association between both alterations ${ }^{3,8,9}$, since mechanisms underlying MetS compromise the blood flow to the penis in numerous ways ${ }^{7}$. Specifically, an association between ED and hypertension ${ }^{10}, \mathrm{~T}^{2} \mathrm{DM}^{11}$, cardiovascular disease and dyslipidemia ${ }^{12}$, obesity, central adiposity ${ }^{13}$ with ED have been described. Recent studies performed in a Mexican population have confirmed that the lack of glycemic control in patients with T2DM increases the risk of developing $\mathrm{ED}^{14}$.

Despite the publication of many studies on the relationship of the different components of the MetS on ED 3,8,15 the topic has not been entirely explored in the Mexican population, nor have the specific components of this syndrome been emphasized or identified as the most commonly associated to ED, its progression and/or severity. Our main objective was to analyze the relationship between MetS and ED in a group of Mexican patients; however, we also intended to study the influence of other morbidity factors on ED, as well as to define the specific MetS components most associated with ED severity and progression. 


\section{Methods}

Design

An observational and cross-sectional study was performed in a group of men (30-60 years old) regularly attending the Urology outpatient service at The National Institute of Nutrition "Salvador Zubirán" between 2014 and 2017. The present work adhered to the Strengthening the Reporting of Observational Studies in Epidemiology (STROBE) statement for observational studies and was approved by the local Ethics Committee (approval number URO-84413/13-1) according to national and international regulations for human studies and the Helsinki Declaration. Informed consent was obtained from all individual participants included in the study.

\section{Participants and settings}

Patients were recruited through a printed announcement at the Urology Department. A total of 126 patients with previous diagnosis of ED were identified. Inclusion criteria considered individuals with or without T2DM (T2DM $<10$ years of evolution), controlled dyslipidemia ( $T G \leq 300 \mathrm{mg} / \mathrm{dL}, \mathrm{LDL}-\mathrm{C} \leq 200 \mathrm{mg} / \mathrm{dL}$, with or without pharmacological treatment), controlled systemic blood pressure $(<140 / 90 \mathrm{mmHg}$ only using one antihypertensive drug) and being overweight or obese (body mass index or BMI $\geq 25$ or $30 \mathrm{~kg} / \mathrm{m}^{2}$, respectively). Exclusion criteria were uncontrolled glycaemia (HbAlc $\geq 8 \%$ ), uncontrolled hypertension (using two or more antihypertensive drugs without reaching treatment goals), pharmacologic treatment for ED, prostate surgery, neuropathy, major depressive disorder (Beck Depression Inventory score >25), high performance athletes, hormonal replacement therapy, pelvic radiotherapy, chronic kidney disease (glomerular filtration rate $<60 \mathrm{ml} / \mathrm{min}$, according to the CKD-EPI formula), uncontrolled dyslipidemia ( $T G \geq 300 \mathrm{mg} / \mathrm{dL}$ or C-LDL $\geq 200 \mathrm{mg} / \mathrm{dL}$ ), possible or diagnosed hypogonadism, hypothyroidism, liver cirrhosis, alcoholism (Alcohol Use Disorder Identification Test score >8), acute myocardial infarction in the last 6 months, anatomical deformity of the sexual organs, and/or incomplete data. We finally included 86 patients.

\section{Clinical and nutritional evaluation}

A Simplified International Index of Erectile Function-5 questionnaire (IIEF-5), was applied to identify severity of ED (mild, mild-moderate, moderate and severe). Tobacco and alcohol consumption were assessed through the Fagerström test and the Alcohol Use Disorders Identification Test (AUDIT), respectively. Depressive behavior which could indirectly modify erectile function was identified by the Beck Depression Inventory (BDI). MetS was 
diagnosed according to the ATP-III criteria (frequently used in patients with ED) ${ }^{3}$. Furthermore, anthropometric measurements (weight, height, neck circumference [NC] and waist circumference [WC]) were performed according to the International Society for the Advancement of Kinanthropometry guidelines. Blood pressure (BP) and the following chemical biomarkers values were drawn from the hospital's medical records: fasting glucose, glycated hemoglobin (HbA1c), total cholesterol (TC), high-density lipoprotein cholesterol (HDL-C), low-density lipoprotein cholesterol (LDL-C), triglycerides (TG), serum testosterone and estradiol concentrations.

\section{Statistical analysis}

Normality test were performed for continuous variables. Means for independent samples were compared through the Student's $t$-test. Linear regression analysis was performed in order to identify risk factors for ED. Beta coefficients with $95 \%$ odds ratio (OR) and confidence intervals $(95 \% \mathrm{CI})$ are shown. A $p<0.05$ value was considered significant. Statistical analysis was performed using the IBM SPSS Statistics ${ }^{\circledR}$ Software version 21.

\section{Results}

One hundred and twenty-six patients were initially considered. We excluded 40 candidates and the remaining 86 participants were classified into two groups according to a positive MetS diagnosis (70.9\%) or not. Clinical characteristics are depicted and compared in table 1. Significant differences in anthropometric parameters (weight, BMI, NC and WC), laboratory values (TG, TC, glucose, and HbA1c), clinical characteristics (BP) and the BDI score were found. However, no differences in the overall IIEF-5 score (13.34 vs 13.76, respectively; $p=0.707)$, neither on the testosterone or estradiol values were detected among participants with or without MetS.

ED severity was classified according to cut-offs points into mild, mild-moderate, moderate and severe ${ }^{16}$ and further analyzed considering the presence of MetS. Patients affected by severe $(n=6,66.7 \%)$ and moderate $(n=13$, 72.2\%) ED were more common in the MetS group. The same analysis was performed with the individual components of the MetS. A more severe ED was identified in patients with a HbA1c $\geq 5.7 \%$ when compared to patients with a normal glucose metabolism (14.6 vs 12.2, $p=0.014$, respectively) (Table 2). The linear regression analysis (Table 3 ) identified both $\mathrm{HbA1c}>5.7 \%$ and fasting glucose $>110 \mathrm{mg} / \mathrm{dL}$ as significant risk factors for the development of $\mathrm{ED}(\mathrm{OR}=48.76,95 \% \mathrm{CI}=3.6-659.26, p=0.004 ; \mathrm{OR}=15.62,95 \% \mathrm{CI}=1.12-250, p=0.04$, respectively). 
Table 1. Comparison of clinical characteristics in patients with erectile dysfunction with or without metabolic syndrome. ${ }^{\mathrm{a}}$

\section{Metabolic Syndrome}

\begin{tabular}{|c|c|c|c|}
\hline Characteristic & $\begin{array}{c}\text { Yes } \\
(n=61)\end{array}$ & $\begin{array}{c}\text { No } \\
(n=25)\end{array}$ & $p$-value \\
\hline Age (years) & $52.6 \pm 9.6$ & $50.4 \pm 8.1$ & 0.28 \\
\hline Weight $(\mathrm{kg})$ & $86.7 \pm 13.1$ & $74.3 \pm 12.5$ & $<0.001$ \\
\hline $\operatorname{BMI}\left(\mathrm{kg} / \mathrm{m}^{2}\right)$ & $30.3 \pm 4.1$ & $26.4 \pm 4.1$ & $<0.001$ \\
\hline $\mathrm{WC}(\mathrm{cm})$ & $105.6 \pm 10.4$ & $95.0 \pm 11.1$ & $<0.001$ \\
\hline $\mathrm{NC}(\mathrm{cm})$ & $42.5 \pm 3.1$ & $39.8 \pm 3.1$ & 0.001 \\
\hline $\mathrm{TG}(\mathrm{mg} / \mathrm{dL})$ & $190.4 \pm 88.9$ & $118.8 \pm 49.7$ & $<0.001$ \\
\hline HDL-C (mg/dL) & $39.6 \pm 8.8$ & $48.6 \pm 8.2$ & $<0.001$ \\
\hline Glucose (mg/dL) & $121.2 \pm 46.4$ & $98.5 \pm 43.3$ & 0.036 \\
\hline $\mathrm{Hb} 1 \mathrm{Ac}(\%)$ & $6.4 \pm 1.4$ & $5.4 \pm 0.8$ & $<0.001$ \\
\hline Total testosterone (ng/dL) & $422.4 \pm 148.3$ & $448.6 \pm 128.3$ & 0.54 \\
\hline Estradiol (pg/mL) & $32.4 \pm 22.1$ & $26.8 \pm 14.2$ & 0.36 \\
\hline $\mathrm{SP}(\mathrm{mmHg})$ & $125.5 \pm 12.2$ & $119.5 \pm 10.9$ & $\mathbf{0 . 0 3 2}$ \\
\hline $\mathrm{DP}(\mathrm{mmHg})$ & $81.8 \pm 8.8$ & $77.4 \pm 7.5$ & 0.024 \\
\hline IIEF-5 (total score) & $13.3 \pm 4.5$ & $13.7 \pm 4.6$ & 0.707 \\
\hline BDI (total score) & $9.8 \pm 7.8$ & $5.5 \pm 4.3$ & 0.002 \\
\hline AUDIT (total score) & $3.2 \pm 4.8$ & $1.8 \pm 2.5$ & 0.091 \\
\hline Fagerström test (total score) & $0.1 \pm 0.7$ & $0 \pm 0$ & 0.055 \\
\hline
\end{tabular}

${ }^{\text {a }}$ Following Adult Panel Treatment III diagnostic criteria.

International System of Units conversions: $1 \mathrm{mg} / \mathrm{dL}$ of $\mathrm{HDL}-\mathrm{C}=0.26 \mathrm{mmol} / \mathrm{L} ; 1 \mathrm{mg} / \mathrm{dL}$ of $\mathrm{TG}=\mathrm{is} 0.01$ $\mathrm{mmol} / \mathrm{L} ; 1 \mathrm{mg} / \mathrm{dL}$ of glucose $=0.06 \mathrm{mmol} / \mathrm{L}$.

Abbreviations: $\mathrm{BMI}=$ body mass index; $\mathrm{WC}=$ waist circumference; $\mathrm{NC}=$ neck circumference; $\mathrm{TG}=$ triglycerides; HDL-C = high-density lipoprotein cholesterol; HbA1c= glycated hemoglobin; $\mathrm{SP}=$ systolic pressure; DP= diastolic pressure; IIEF-5= International Index of Erectile Function-5; BDI= Beck's Depression Inventory; AUDIT= Alcohol Use Disorders Identification Test. 


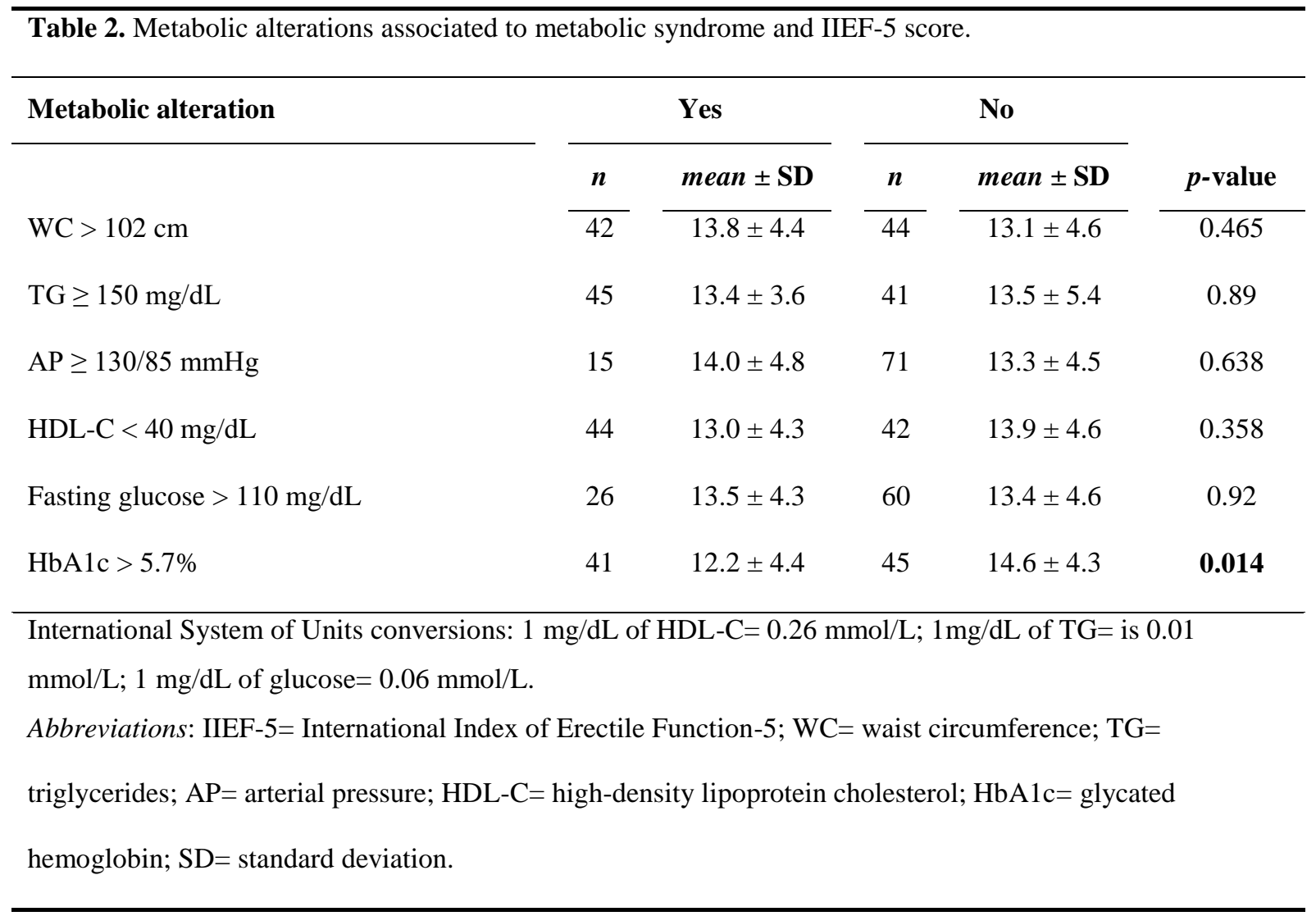


usually show glycemic dysregulation secondary to the elevation of serum free fatty acids (induced by apoptosis of the pancreatic $\beta$-cells), leptin and TNF- $\alpha$ concentrations (which both restricts insulin secretion), altogether subsequently reducing the insulin secretory capacity ${ }^{18}$.

Méndez-Hernández and colleagues ${ }^{19}$ described that individuals classified as having undesirable eating habits have an $8.8(95 \% \mathrm{CI}=3.1-25)$ and $11.1(95 \% \mathrm{CI}=3.4-36.1)$ higher risk of developing MetS (considering NCEPATP III and International Diabetes Federation criteria, respectively); and $11.2(95 \% \mathrm{CI}=3.9-31.5)$ higher probability of presenting insulin resistance, when compared with individuals with healthier eating habits. Consequently, subjects with undesirable eating habits are also predisposed to develop ED, which could explain the large prevalence of ED found among our Mexican patients ${ }^{4,5}$.

Furthermore, our results agree with those published by Chao and colleagues, who found a significant association between anthropometric parameters such as central obesity (for Asian population, WC $\geq 90 \mathrm{~cm}$ ) and ED $(p=0.007)^{20}$. Other studies in different populations have shown this particular relationship ${ }^{21}$. However, in contrast to our results, there is evidence on a significant difference in IIEF-5 score between men without and with MetS (21.76 \pm 3.59 vs $18.26 \pm 5.08$ respectively, $p<0.001$ ), possibly indicating that ED prevalence raises when a patient exhibits more components of the MetS ${ }^{20}$.

Regarding arterial hypertension, a multicenter cross-sectional study ${ }^{22}$ that recruited 512 hypertensive patients and applied the IIEF-5 questionnaire found a prevalence of ED of 46.5\%, which resembles that found on our study. However, existing literature does not provide conclusive evidence on the association between depression, MetS and ED. In a prospective study in patients with MetS $(n=5,232)$, only central obesity, high triglycerides' concentration, and low HDL-C concentration predicted depression symptoms ${ }^{23}$. Our results found a trend toward depression development in patients with MetS diagnosed by BDI.

Our biochemical results match those reported in a systematic review and meta-analysis published by Besiroglu and colleagues ${ }^{21}$ where a positive association between ED and hyperlipidemia was shown. A prospective study in a cohort of men, found that hypercholesterolemia is a long-term ED predictor ${ }^{24}$. Moreover, data from experimental models have found that the atherosclerotic process caused by hypercholesterolemia affects the corpus cavernous, and that the reduction of serum cholesterol normalizes the cavernous relaxation, therefore suggesting that the cavernous' smooth muscle dysfunction caused by hypercholesterolemia is reversible ${ }^{25}$. In this context, a 
prospective clinical trial evaluated the cardiovascular risk factors impact on erectile function. Authors concluded that age, BMI, TC, and TG concentrations were significantly associated to $\mathrm{ED}^{12}$.

With respect to glycemic lack of control, Maseroli and colleagues showed a higher prevalence of hyperglycemia (fasting glucose $>100 \mathrm{mg} / \mathrm{dL}$ ) in patients with sexual dysfunction than in patients without it (44.5 vs $33.3 \%, p<0.05)^{26}$. Specifically, these authors found a direct relationship between a higher serum glucose concentration and the development of ED. Furthermore, Pohjantähti-Maaroos and colleagues analyzed 57 subjects with MetS and compared them with 48 physically active individuals, and found that ED was more often among the MetS group and that patients with EC showed a higher serum glucose concentration than those not having MetS $\left(6.99 \pm 2 \mathrm{mmol} / \mathrm{L}\right.$ vs $6.54 \pm 1 \mathrm{mmol} / \mathrm{L}$, respectively) $(p<0.001)^{27}$. Additionally, Xu and colleagues recruited patients with T2DM and evaluated ED (IIEF-5) and concluded that the ED risk was higher among patients with worse glycemic control ${ }^{28}$. In addition, an observational study in a Mexican population where HbA1c concentrations were associated to the IIEF-5 overall score found an odds ratio of 6.92; in this set of patients, the prevalence of ED was $72 \%$ and the lack of glycemic control was observed in $80.9 \%$ of the patients ${ }^{14}$. Similar results were found in our study, concluding that $\mathrm{Hb} 1 \mathrm{Ac}>5.7 \%$ and/or fasting glucose $>110 \mathrm{mg} / \mathrm{dL}$ may influence directly the ED severity among patients with MetS.

Although it is well known that ED is potentially caused by testosterone deficiency, hypogonadism and age, and that long-term benefit of testosterone replacement has been addressed ${ }^{12,29}$, our results do not show a relationship between the testosterone concentrations below $346 \mathrm{ng} / \mathrm{dL}(12 \mathrm{nmol} / \mathrm{L})$ and the development of ED among patients with MetS, nor do corroborate an etiological association between the patients age and the development of ED. Nonetheless, hyperglycemia promotes alterations in the concentrations of nitric oxide, cyclic guanosine monophosphate (cGMP), free radicals, and in the endothelin B biosynthesis, all of them possible direct causes of $\mathrm{ED}^{14}$. In consequence, in this particular group of patients, the etiology of ED is closely related to different factors specifically associated to glycemic dysregulation. However, both adipose tissue-derived hormones -also associated to insulin resistance- and vascular disease compromise blood flow to the penis and are presumably caused by nitric oxide synthase inhibition; thereof, adipokines should be considered among patients with ED and MetS for a global physiopathological understanding ${ }^{30}$.

Our study provides evidence of the MetS as a risk factor for the development and progression of ED that may be extrapolated to other Hispanic populations. Despite these findings coincide partially with the existing evidence ${ }^{9,15}$, 
we reinforce the hypothesis that hyperglycemia promotes the development of ED. Standards for the prevention and treatment focused on metabolic and glycemic control are fundamental for erectile function improvement. However, we acknowledge our sample size as a limitation of our study, explained by the lack of interest to participate of the population addressed, which could in turn reduce the statistical reliability of our study (confidence intervals in table 3 addressed), as well as the transversal and observational nature of our design. Nevertheless, the statistical analysis remains valid and relevant to this particular population; thus, both limitations are not major concerns. Further studies including other glucose metabolism indicators (e.g. insulin), adipokines (leptin and adiponectin), inflammation markers (IGF-1) and the exploration of psychogenic ED causes are warranted in order to complement our findings.

\section{Conclusions}

MetS components converge directly into the severity of ED, particularly hyperglycemia manifested by $\mathrm{Hb} 1 \mathrm{Ac}$ $>5.7 \%$ and/or fasting glucose $>110 \mathrm{mg} / \mathrm{dL}$. Such results agree with those previously published elsewhere; however, our study provides a specific description of the influence of each MetS component on the severity of ED. It is therefore necessary to generate population-based guidelines and recommendations in order to develop a multidisciplinary treatment for ED that may address the importance of the MetS prevention by promoting an adequate lifestyle among Latin-American men. The present study enables that labor by strongly suggesting the inclusion of basal glucose and/or Hb1 Ac as a complementary biochemical screening for ED.

\section{Acknowledgments}

We thank our colleagues BSc. Marco Antonio Rivera-Valencia, BSc. Kevin Alfonso Lozano-Martínez, BSc. Itzel Salcedo- Grajales, BSc. Griselda López-Córdova, BSc. Laura Olivia Herrera-Gazca, BSc. Brenda Salazar-Ruiz, and BSc. David Humberto Gutiérrez-Dominguez for their contribution on the data collection. 


\section{References}

1. Grundy SM. Metabolic syndrome update. Trends Cardiovasc Med 2016;26:364-373. https://doi.org/10.1016/j.tcm.2015.10.004.

2. National Cholesterol Education Program. Report of the Expert Panel on Population Strategies for Blood Cholesterol Reduction: Executive Summary. Arch Intern Med 1991;151:1071. https://doi.org/10.1001/archinte.1991.00400060019005.

3. Gorgel SN, Gorgel A, Sefik E. Sexual function in male patients with metabolic syndrome and effective parameters on erectile dysfunction. Int Braz J Urol 2014;40:56-61. https://doi.org/10.1590/S16775538.IBJU.2014.01.08.

4. Rojas R, Aguilar-Salinas CA, Jimenez-Corona A, Shamah-Levy T, Rauda J, Avila-Burgos L, et al. Metabolic syndrome in Mexican adults: results from the National Health and Nutrition Survey 2006. Salud Publica Mex 2010;52:S11-8.

5. Salas R, Bibiloni MDM, Ramos E, Villareal JZ, Pons A, Tur JA, et al. Metabolic syndrome prevalence among Northern Mexican adult population. PLoS One 2014;9:e105581. https://doi.org/10.1371/journal.pone.0105581.

6. Wentzell E, Salmerón J. Prevalence of erectile dysfunction and its treatment in a Mexican population: distinguishing between erectile function change and dysfunction. J Mens health 2009;6:56-62. https://doi.org/10.1016/j.jomh.2008.09.009.

7. Yafi FA, Jenkins L, Albersen M, Corona G, Isidori AM, Goldfarb S, et al. Erectile dysfunction. Nat Rev Dis Primers 2016;2:16003. https://doi.org/10.1038/nrdp.2016.3.

8. Borges R, Temido P, Sousa L, Azinhais P, Conceição P, Pereira B, et al. Metabolic Syndrome and Sexual (Dys)function. J Sex Med 2009;6:2958-2975. https://doi.org/10.1111/j.1743-6109.2009.01412.x.

9. Bal K, Öder M, Şahin AS, Karataş CT, Demir O, Can E, et al. Prevalence of Metabolic Syndrome and Its Association with Erectile Dysfunction Among Urologic Patients: Metabolic Backgrounds of Erectile Dysfunction. Urology 2007;69:356-360. https://doi.org/10.1016/j.urology.2006.09.057.

10. Ning L, Yang L. Hypertension might be a risk factor for erectile dysfunction: a meta-analysis. Andrologia 2017;49:1-10. https://doi.org/10.1111/and.12644.

11. Kouidrat Y, Pizzol D, Cosco T, Thompson T, Carnaghi M, Bertoldo A, et al. High prevalence of erectile 
dysfunction in diabetes: a systematic review and meta-analysis of 145 studies. Diabet. Med 2017;34:11851192. https://doi.org/10.1111/dme.13403.

12. Gandaglia G, Briganti A, Jackson G, Kloner RA, Montorsi F, Montorsi P, et al. A systematic review of the association between erectile dysfunction and cardiovascular disease. Eur Urol 2014;65:968-978. https://doi.org/10.1016/j.eururo.2013.08.023.

13. Traish AM, Feeley RJ, Guay A. Mechanisms of obesity and related pathologies: Androgen deficiency and endothelial dysfunction may be the link between obesity and erectile dysfunction. FEBS J 2009; 276:57555767. https://doi.org/10.1111/j.1742-4658.2009.07305.x.

14. Figueroa-García J. Pérez AJ. Association of glycemic control and erectil dysfunction in diabetic patients. Rev Mex Urol 2017;77:5-11.

15. Chen K, Mi H, Gao Y, Tan A, Lu Z, Wu C, et al. Metabolic syndrome: A potential and independent risk factor for erectile dysfunction in the chinese male population. Urology 2012;80:1287-1292. https://doi.org/10.1016/j.urology.2012.08.028.

16. RC Rosen, JC Cappelleri, Smith MD, Lipsky J, Peña BM. Development and evaluation of an abridged , 5item version of the International Index of Erectile Function ( IIEF-5 ) as a diagnostic tool for erectile dysfunction. Int J Impot Res 1999;11:319-326.

17. Gutiérrez JP, Rivera-Dommarco J, Shamah-Levy T, Villalpando-Hernández S, Franco A C-NL, RomeroMartínez M H-ÁM. Encuesta Nacional de Nutricion y Salud. 2012;1-200.

18. Hajer GR, Van Haeften TW, Visseren FLJ. Adipose tissue dysfunction in obesity, diabetes, and vascular diseases. Eur. Heart J 2008;29:2959-2971. https://doi.org/10.1093/eurheartj/ehn387.

19. Méndez-Hernández P, Dosamantes-Carrasco LD, Siani C, Pierlot R, Martínez-Gómez M, Rivera-Paredez B, et al. Mealtime habits and risk of developing the metabolic syndrome or insulin resistance among Mexican adults. Br J Nutr 2016;116:1824-1833. https://doi.org/10.1017/S0007114516003329.

20. Chao JK, Kuo WH, Chiang HS, Hwang TI, Chao IC, Chiang SK, et al. Association of metabolic syndrome, atherosclerosis risk factors, sex hormones in ED in aboriginal Taiwanese. Int J Impot Res 2012; 24:141-146. https://doi.org/10.1038/ijir.2012.5.

21. Besiroglu H, Otunctemur A, Ozbek E. The Relationship Between Metabolic Syndrome, Its Components, and Erectile Dysfunction: A Systematic Review and a Meta-Analysis of Observational Studies. J Sex Med 
2015;12:1309-1318. https://doi.org/10.1111/jsm.12885.

22. Cuéllar de León AJ, Ruiz García V, Campos González JC, Pérez Hoyos S, Brotons Multó F. Prevalencia de disfunción eréctil en pacientes con hipertensión arterial. Med Clin (Barc) 2002;119:521-526. https://doi.org/10.1016/S0025-7753(02)73483-0.

23. Akbaraly TN, Kivimäki M, Brunner EJ, Chandola T, Marmot MG, Singh-Manoux A, et al. Association between metabolic syndrome and depressive symptoms in middle-aged adults. Diabetes Care 2009;32:499504. https://doi.org/10.2337/dc08-1358.

24. Fung MM, Bettencourt R, Barrett-Connor E. Heart disease risk factors predict erectile dysfunction 25 years later: The Rancho Bernardo Study. J Am Coll Cardiol 2004;43:1405-1411. https://doi.org/10.1016/j.jacc.2003.11.041.

25. Kim JH, Klyachkin ML, Svendsen E, Davies MG, Hagen PO, Carson CC. Experimental hypercholesterolemia in rabbits induces cavernosal atherosclerosis with endothelial and smooth muscle cell dysfunction. J Urol 1994;151:198-205. https://doi.org/10.1016/S0022-5347(17)34916-9.

26. Maseroli E, Corona G, Rastrelli G, Lotti F, Cipriani S, Forti G, et al. Prevalence of endocrine and metabolic disorders in subjects with erectile dysfunction: A comparative study. J Sex Med 2015;12:956-965. https://doi.org/10.1111/jsm.12832.

27. Pohjantähti-Maaroos H, Palomäki A, Hartikainen J. Erectile dysfunction, physical activity and metabolic syndrome: Differences in markers of atherosclerosis. BMC Cardiovasc Disord 2011;11:36. https://doi.org/10.1186/1471-2261-11-36.

28. $\mathrm{Xu} \mathrm{Y,} \mathrm{Zhang} \mathrm{Y,} \mathrm{Yang} \mathrm{Y,} \mathrm{Liu} \mathrm{L,} \mathrm{Chen} \mathrm{Y,} \mathrm{Liu} \mathrm{X.} \mathrm{Prevalence} \mathrm{and} \mathrm{correlates} \mathrm{of} \mathrm{erectile} \mathrm{dysfunction} \mathrm{in} \mathrm{type} 2$ diabetic men : a population-based cross-sectional study in Chinese men. Int J Impot Res 2019;31:9-14. https://doi.org/10.1038/s41443-018-0060-4.

29. Pagano MJ, De Fazio A, Levy A, RoyChoudhury A, Stahl PJ. Age, Body Mass Index, and Frequency of Sexual Activity are Independent Predictors of Testosterone Deficiency in Men With Erectile Dysfunction. Urology 2016; 90:112-118. https://doi.org/10.1016/j.urology.2015.12.030.

30. Dozio E, Barassi A, Dogliotti G, Malavazos AE, Colpi GM, D'Eril GV, et al. Adipokines, Hormonal Parameters, and Cardiovascular Risk Factors: Similarities and Differences Between Patients with Erectile Dysfunction of Arteriogenic and Nonarteriogenic Origin. J Sex Med 2012;9:2370-7. 
https://doi.org/10.1111/j.1743-6109.2012.02781.x. 